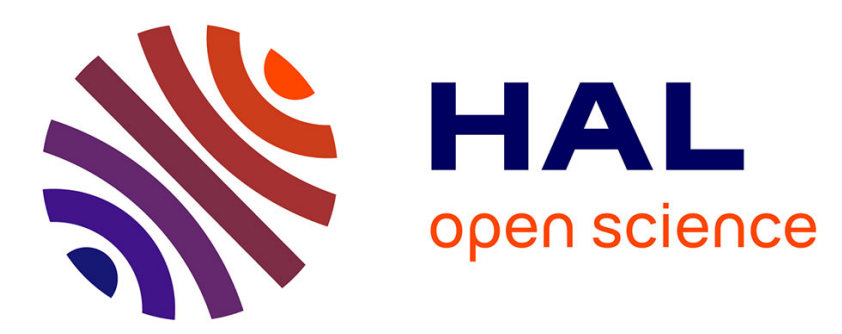

\title{
Precipitation study in thin layers by grazing small-angle scattering of X-rays
}

T. Slimani, N. Thoft, A. Naudon

\section{To cite this version:}

T. Slimani, N. Thoft, A. Naudon. Precipitation study in thin layers by grazing small-angle scattering of X-rays. Journal de Physique IV Proceedings, 1993, 03 (C8), pp.C8-303-C8-306. 10.1051/jp4:1993860 . jpa-00252291

\section{HAL Id: jpa-00252291 https://hal.science/jpa-00252291}

Submitted on 1 Jan 1993

HAL is a multi-disciplinary open access archive for the deposit and dissemination of scientific research documents, whether they are published or not. The documents may come from teaching and research institutions in France or abroad, or from public or private research centers.
L'archive ouverte pluridisciplinaire HAL, est destinée au dépôt et à la diffusion de documents scientifiques de niveau recherche, publiés ou non, émanant des établissements d'enseignement et de recherche français ou étrangers, des laboratoires publics ou privés. 


\title{
Precipitation study in thin layers by grazing small-angle scattering of X-rays
}

\author{
T. SLIMANI, N.B. THOFT* ${ }^{*}$ and A. NAUDON
}

Laboratoire de Métallurgie Physique, URA 131 du CNRS, Université de Poitiers, 40 avenue du Recteur Pineau, 86022 Poitiers cedex, France

* Physics Department, Risø National Laboratory, 4000 Roskilde, Denmark

\begin{abstract}
Studies of thin layer by small-angle scattering of X-rays in the transmission mode give weak intensities because the X-ray path is short. Grazing-incidence X-ray scattering circumvents this difficulty for the analysis of a thin layer deposited on a substrate. Furthermore, for a bulk sample, grazing incidence is the only way to study the surface layer, and the penetration depth can be controlled by the incidence angle of the X-ray beam. In this study, we report on krypton and xenon bubbles which are precipitated in an aluminium single crystal and also in polycristaline deposited layers of metals. These inclusions are produced by ion implantation at room temperature. They are found solid by high-angle diffraction. Comparison between high-angle diffraction and small-angle scattering under grazing incidence lead to a better knowledge of these specific precipitated systems.
\end{abstract}

\section{Introduction}

While there is a lot of papers on grazing-incidence X-ray diffraction and X-ray reflectometry which have been widely applied to the study of surfaces, thin layers and multilayers in recent years, after early pioneering work of Parratt [1] in 1954, only a few papers deal with grazing-incidence smallangle X-ray scattering. Two different approaches of SAS under grazing incidence have to be considered: the first one developed by our group [2] applies for layers and surface layers having thicknesses of at least $100 \mathrm{~nm}$. Here the q vector is perpendicular to the surface of the sample, and consequently information is obtained in the growth direction. The second one, developed by Levine and Cohen [3] deals with clusters deposited on a flat surface.

In the present paper the possibilities and limitations of grazing-incidence SAS of X-rays, with $q$ vector perpendicular for the study of surface layers (deposited or constituting the surface of a bulk sample) will be described. Examples of precipitated inclusions of rare gases, produced by implantation will be shown.

Less than 10 years ago, the study of the behaviour of inert gases in metals has led to the exciting discovery of solid inert-gas "bubbles" in aluminium at room temperature. In two independent studies in the year 1984 (Vam Felde et al. [4], Templier et al. [5]) three-dimensional precipitates of solid xenon have been observed after implantation of the ion into aluminium. The solid inert-gas had a fcc epitaxial structure with the host matrix. Extension of this research to other metals showed that $\mathrm{Kr}$ bubbles in $\mathrm{Cu}$, $\mathrm{Ni}$ and $\mathrm{Au}$ are in the solid phase [6] and in epitaxy with the host matrix. This is a general trend for such inclusions of rare gases in metals.

There has been a large effort using electron microscopy and electron diffraction technique concerning the study of these solid inert-gas clusters or precipitates. Melting of the krypton or xenon on heating (and its crystallisation on cooling) has been followed in electron microscopy diffraction patterns [6,7]. All these investigations produced direct evidence for a high pressure (1-2 Gpa) in the small bubbles formed after implantation of inert-gas ions into metals at ambient temperature.

$\mathrm{X}$-ray diffraction investigation of ion implantation has also been used and has shown that epitaxial inclusions of krypton or xenon in aluminium single crystals could be seen [8]. In the present paper we shall see that small-angle X-ray scattering under grazing incidence could be successfully used in such studies. It can give more accurate values of the size of the inclusions. 


\section{The principle of GISAXS with $\mathrm{q}^{\perp}$}

Consider the situation depicted in fig. 1 where a narrow and parallel beam impinges on the point $O$ on the flat surface (plane (P) defined by its normal $n$ ) of a layer with an angle of incidence $\alpha_{i}$ higher than $\alpha_{\mathrm{c}}$.

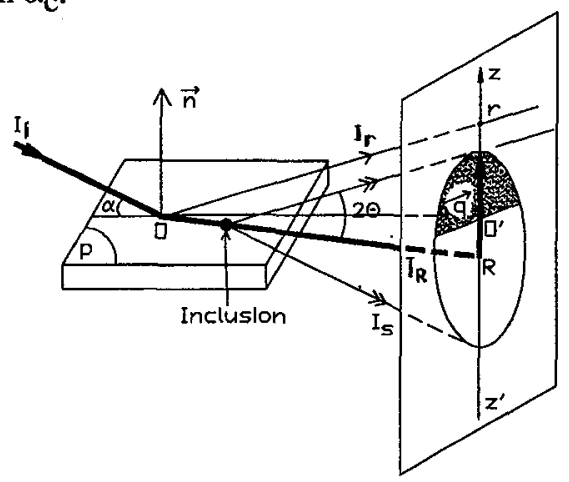

Fig.1 : Grazing incidence geometry with the $\mathrm{q}$ vector perpendicular to the surface $(P)$ of the layer; the angle of incidence $\alpha_{i}$ is higher than $\alpha_{c}$. Refraction of the scattered X-rays is neglected for clarity.

When the refracted beam $I_{R}$, traveling just under the surface of the layer, encounters a small particle of electronic density different from that of the material constituting the surface layer, it acts as a primary beam and gives rise to a SAXS signal due to the encountered particle; this is what we call small-angle scattering under grazing incidence (GISAXS). Its angular origin in the registration plane (Q) perpendicular to the surface plane $(P)$ is the point $R$ on the axis $z^{\prime} z$ perpendicular to $(P)$.

Due to the imaginary part of the refractive index, $\beta$, the refracted beam $I_{R}$ is exponentially damped as a function of a distance below the surface. Nevertheless, the scattering can be measured when the scattered bodies in the layer are small enough, their scattering being given by a set of scattering cones of half-angle $2 \theta$ (only one is drawn in fig.1). In such a case, the intensities lies above the plane of the layer (the hatched part). It is also seen that the maximum $\mathrm{q}$ vector which can be measured is the one indicated, that is to say when it is along $z^{\prime} z$.

\section{Experimental results}

\section{1) Implantation in evaporated layers}

Thin layers of nickel and copper were obtained by electron-gun evaporation on silicon wafers (either (111) or (200) orientation). The thickness of these layers was of about $1000 \AA$ for an optimum implantation with $300 \mathrm{KeV}$ ions. Xenon or krypton ions were implanted at room temperature and at moderate fluence in the range $10^{16} \mathrm{ions} / \mathrm{cm}^{2}$.

Figure 2 shows the diffraction curve of a copper layer, obtained under a grazing incidence $\alpha=1^{\circ}$, with our diffractometer adapted for this purpose and described elsewhere [2]. The broad halo centered around $2 \theta=26^{\circ}$ indicates that xenon is precipitated in solid form, but, as the metallic layer is polycristalline, this diffraction halo is smeared by both (111) and (200) streaks of xenon, whose theoretical $2 \theta$ values are $24.5^{\circ}$ and $28.6^{\circ}$ respectively.

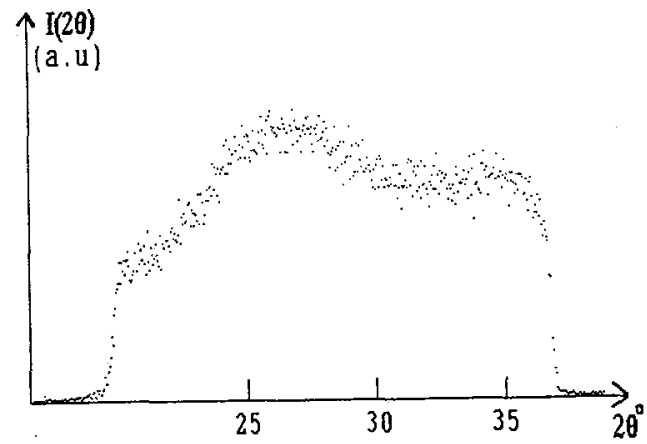

Fig. 2 : Diffraction curve with $\alpha=1^{\circ}$ of a copper layer implanted with xenon ions (energy of $300 \mathrm{KeV}$ and fluence of $2 \times 10^{16}$ ions $/ \mathrm{cm}^{2}$ 
Concerning the small-angle scattering curve obtained at grazing incidence, the xenon response is not well seen because a residual reflected beam of the silicon wafer is always present at grazing incidence and masks the scattering of the xenon inclusions. Furthermore, heating of such samples, in order to follow the evolutions of the inclusions, led to silicide formation at the layer-substrate interface (as a result of the ion-induced cascades) when reaching temperatures up to $400^{\circ} \mathrm{C}$. This is the reason why we tried the same experiments with bulk materials.

\section{2) Implantation of xenon in bulk copper}

Disks of high-purity copper have been mechanically polished on one face (finishing with 1 um diamond paste) for grazing-incidence experiments. The quality of the surface is not as good as the one of the silicon wafer, but the advantage is that we have no residual reflected beam due to the roughness of the surface. So, a SAXS response is obtained for an angle of incidence $\alpha=1.2^{\circ}$. Fig. 3 shows the scattering curves for the as-implanted sample and also the same sample annealed at $500^{\circ} \mathrm{C}$ for $30 \mathrm{~min}$.

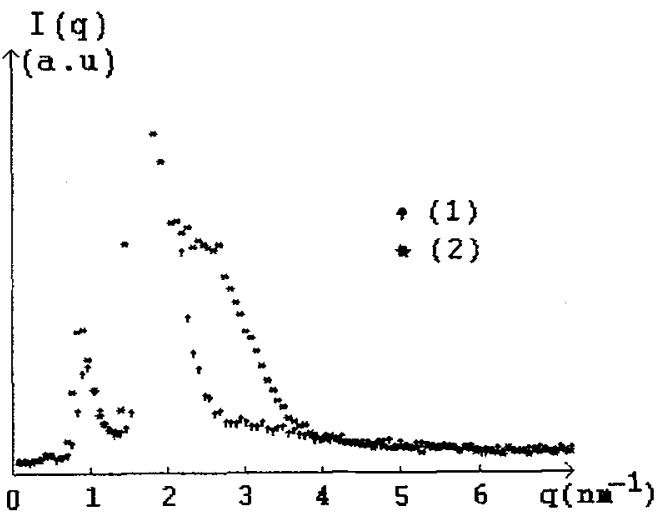

Fig. 3 : SAXS curves under incidence $\alpha=$ $1.2^{\circ}$ of bulk copper. (1) as-implanted sample; (2) after annealing at $500^{\circ} \mathrm{C}$ for 30 minutes.

There is a strong scattering near the angular origin (not represented on the figure) which is due to the roughness of the surface. The shouldering observed at larger angles (which becomes a maximum after subtraction) indicates a spatial correlation between xenon precipitates. The values are 18 and $28 \AA$ before and after annealing respectively. Concerning the size of the precipitates, plot of $\log I(q)$ versus $\mathrm{q}^{2}$ gives the radius of gyration which is 6 and $10 \AA$ before and after annealing respectively.

The diffraction curves for these samples, under a grazing-incidence $\alpha=1.2^{\circ}$, display a scattering pattern similar to that of Fig. 2, indicating the presence of very small xenon precipitates.

\section{3) Implantation in an Al single crystal}

Disks of diameter $9 \mathrm{~mm}$ with [111] and [100] normal were cut from an aluminium single crystal. After mechanical polishing and electropolishing, the disks were implanted at room temperature with krypton at an energy of $200 \mathrm{KeV}$ and a fluence of $2 \times 10^{16} \mathrm{at} / \mathrm{cm}^{2}$.

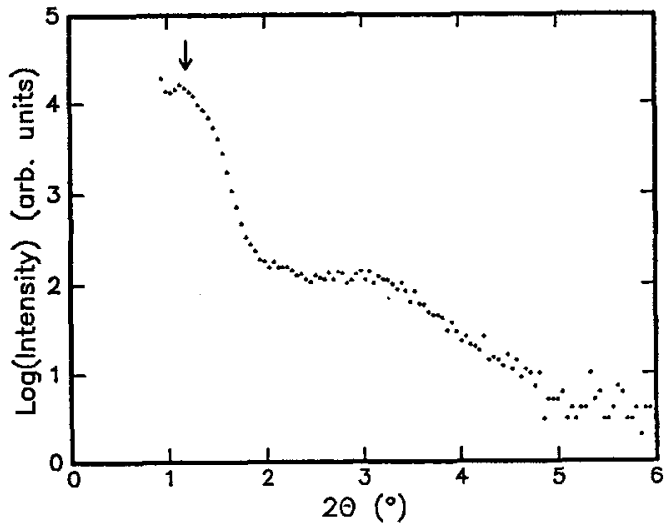

Fig. 4 : GISAXS curve of a (100) Al single crystal implanted with $2 \times 10^{16}$ krypton ions at $200 \mathrm{KeV}$. The accumulation time is 10 $\min$. 
Fig. 4 shows the GISAXS curve of an implanted (100) aluminium single crystal. The angle of incidence is $\alpha_{i}=0.6^{\circ}$. As for the scattering curve of this sample before implantation, it is seen the residual reflected beam for an angle $2 \theta=1.2^{\circ}$ (twice the value of the incident angle) which confirms the good surface quality (flatness) of this sample.

The main point to be seen on this scattering pattern is that, without subtraction of the curve before implantation, a scattering maximum is visible at an angle $2 \theta=2.95^{\circ}$. This value gives a spatial distance between precipitated inclusions $\Lambda=30 \AA$. Their radius of gyration is $R_{g}=11 \AA$. Let us note that the determination of the radius of gyration is only valid for small $2 \theta$ angles (which cannot be obtained under grazing incidence), and that it does not give a true value of the size, especially in an implanted sample where the concentration profile of the ions is not uniform; nevertheless it gives a size indication. Furthermore, $R_{g}$ always overestimated the size of the precipitates, as for Guinier-Preston zones in aluminium-based alloys [9].

After annealing of a similar sample for 30 minutes at $375^{\circ} \mathrm{C}$, the scattering due to the inclusions is shifted towards the angular origin, as a consequence of the growth of these inclusions. The values are : $\Lambda=42 \AA$ and $R_{\mathrm{g}}=12.5 \AA$

High-angle diffraction spectra were measured at the same time as the small-angle scattering curves. They show a broad scattering around the diffraction peak of aluminium and also the weak scattering peak of krypton. These diffraction peaks confirm the presence of epitaxial inclusions of krypton which are precipitated in the Al single crystal. So, combining high-angle and small-angle scattering curves allows to obtain a better knowledge of these rare-gas inclusions which are precipitated in single crystals. These results will be given in a forthcoming paper.

\section{Conclusion}

It has been shown in this paper that grazing-incidence small-angle scattering is a useful method to analyse small precipitated inclusions in a thin layer of a flat bulk sample. It provides size parameters of the scattering objects. This is a non-destructible method for studying a single crystal, but the flatness of the surface is a very important parameter in order to approach the lowest exit angles. For rare-gas precipitation in single crystals, comparison between high-angle diffraction and small-angle scattering under grazing incidence (which is under way) will lead to a better knowledge of these specific precipitated systems.

There is also a limitation for this technique when scattering objects become large; their scattering shifts towards the angular origin, and, due to refraction, it is not possible to obtain reliable data at low angles.

Acknowledgments :

We would like to thank E. Johnson from Niels Bohr Institute of Copenhagen and J. Bohr from Riso National Laboratory for providing the aluminium single crystals. Thanks are due also to C. Templier in Laboratoire de Métallurgie Physique who performed the rare gas implantations.

\section{References}

[1] PARRATT, R.J., Phys. Rev., 95, (1954) 359-369.

[2] NAUDON, A., SLIMANI,T. and GOUDEAU, P. J. Appl. Cryst. 24, (1991), 501.

[3] LEVINE, J.R., COHEN, J.B., CHUNG, Y.W. \& GEORGOPOULOS, P., J. Appl. Cryst. 22, (1989).528-532.

[4] VOM FELDE, A., FINK, J., MULLER-HEINZERLING, T., PFLUGER, J., SCHERRER, B. and LINKER, G., Phys. Rev. Lett., 53 (1984), 922.

[5] TEMPLIER, C., JAOUEN, C., RIVIERE, J.P., DELAFOND, J. and GRILHE, J., C.R. Acad. Sci. Paris, 299, (1984), 613.

[6] EVANS, J.H., and MAZEY, D.J., J. Phys. F :Metal. Phys., 15 (1985), L1.

[7] TEMPLIER, C., GAREM, H. and RIVIERE, J.P., Phil. Mag. A, 53, (1987), 667.

[8] ANDERSEN, H.H., BOHR, J., JOHANSEN, A., JOHNSON, E., SARHOLT-KRISTANSEN, L. and SURGANOV, V., Phys. Rev. Lett., 59, (1987), 1589.

[9] GEROLD. V., in "Small-Angle X-ray Scattering", ed. Brumberger, Gordon and Breach, Sc. Publishers, (1987), p.277. 